\title{
Impact of Real-time Project Control on Capital Project Cost and Schedule Performance
}

\author{
David Grau \\ School of Sustainable Engineering and \\ the Built Environment ; Arizona State \\ University; Tempe AZ, USA \\ david.grau@asu.edu
}

\author{
Amin Abbaszadegan \\ School of Sustainable Engineering and \\ the Built Environment; Arizona State \\ University; Tempe AZ, USA \\ aabbaszi@asu.edu
}

DOI 10.5592/otmcj.2015.2.3

Research paper
THIS ARTICLE ASSESSES THE COMBINED INFLUENCE OF INFORMATION INTEGRATION AND AUTOMATED DATA ANALYTICS ON PROJECT PERFORMANCE. To this end, retrospective data on 78 completed projects, with a total installed value of $\$ 8$ billion, was collected. The level of internal and external information integration and automated analytics were used as surrogates of real-time project controls for statistical analyses purposes. Indeed, non-parametric statistical techniques were used to assess the impact of such technologies on cost and schedule performance. Overall, teams with a sophisticated degree of information integration and automated data analytics can control their projects with more reliable information and in a proactive manner so that informed decisions can be timely made on behalf of the project and the organization.

\section{Keywords}

Real-time; Project controls; Cost; Schedule;

Performance; Project management 


\section{INTRODUCTION}

Despite advancements in construction technology, project management strategies and information systems, the performance of capital projects remains a major issue. The importance of project controls becomes evident after examining construction project risks and uncertainties (Rozenes, 2006). Perhaps the construction industry more than others is susceptible to risks due to the complexity, uncertainty, dynamism, and inherent defragmentation (Thompson and Perry, 1992; Nieto-Morote and Ruz-Vila, 2011). As a consequence, time and cost deviations are still a common realty in the delivery of capital projects (Toor and Ogunlana 2008).

Indeed, cost and schedule deviations at completion, relative to baseline values, are endemic in the construction industry (Ibbs 2013; Mulva and Dai 2012; Gunduz and Hanna 2005; Chang 2002; Ye et al. 2014; Grau and Back 2015). The performance of construction projects deviates all too often from baseline targets and/or plans. However, such deviations are commonly not timely ascertained by project teams, so that corrective actions are often too late or ineffective. Surprises regarding the cost and schedule outcomes at completion during advance or late construction stages are common (Back and Grau 2013). Part of this record of low performance can be attributed to the ineffective control of the project status condition. Typically, controls information on the status of a project is first reported on a monthly basis, and the control information escalates through chains of management at stakeholder organizations during consecutive reporting efforts. In this study, we have documented cases in which upper managers were making decisions on project information that was six months old. This inability to become proactive, rather than reactive, impairs the decision making process and the ability to deliver projects with the expected cost and time outcomes (Grau and Back 2015). We have found that construction experts consensually understand that an instantaneous, or at least timely, project control capability can be a significant improvement and can result in substantial benefits to project performance and project stakeholders. Thus, a potential solution, which becomes the focus of this study, is to leverage advanced information technologies to control projects in a more timely, or instantaneous, manner.

In reality, though, the adoption of new technologies in the capital projects industry has been slower than in other industries, such as manufacturing. Too often the return on investment of information technologies is not evaluated due to the perceived difficulty of such evaluation effort (Johnson and Clayton, 1998). As such, the capital projects industry needs to quantify the costs, benefits, and business implications of real-time project controls with the support of information technologies. For similar reasons several other scholars have attempted to partially identify and quantify the benefits from the adoption of these technologies, and understand whether information technologies can positively impact project performance.

In response to the above challenge, the research herein contributes to the body of knowledge by providing a practical understanding of the effect of information integration and automated analytics capabilities in support of the updated control of project cost and schedule performance. Recent research in the field of monitoring and controls have ranged from productivity improvements (Grau \& Caldas, 2009; Choo et al., 1999), forecasting (Barraza et al., 2000; Kim \& Reinschmidt, 2009), or automation (Grau et al., 2012; Azimi et al., 2011). Despite these endeavours, project managers and contractors are still struggling with tracking and controlling projects in an accurate and timely manner (Elbeltagi and Dawood, 2011). The understanding of impacts from information integration and automated analytics, if any, on project performance can allow management to realize the benefits of implementing such technologies, and hence support decisions on whether or not to incorporate new technologies in order to streamline the stagnant project reporting process.

\section{Background}

Both academics and practitioners have expressed their interest in improving capital project performance by addressing the problem of time lag between current project status and control information reports. Cabano (2003), based on survey research, concluded that there is stagnation or even decline in project control capability. The survey results indicated that only $25 \%$ of owners and contractors are satisfied with the current state of their project control practices. Project managers and contractors are still struggling with tracking and controlling underlying issues that directly or indirectly affect performance (Elbeltagiand Dawood, 2011). Despite advancements in project management strategies and information technologies, the performance of capital projects remains a major issue. The accurate and timely control of project cost and schedule performance is of upmost importance in today's ever competitive industry landscape.

Indeed, the timely delivery of information plays a crucial role in achieving project objectives because it enables appropriate decision-making (Rojas, 1999; Abudayyeh, 2001). Around $50-80 \%$ of the issues affecting construction sites are attributed to missing and/or delayed information access (Howell and Ballard, 1997; Thomas et al., 1997). The more the delay in the identification of performance issues or issues affecting performance, the more challenging, unfeasible, 
and costly that is to apply corrective actions. It is estimated that $12.4 \%$ of project resources are depleted due to late delivery of information to the decision authority, defective materials, and/or rework late in the construction phase (Burati et al., 1992). Arnold \& Javernick-Will (2012) found that data re-entry is the most common source of inefficiency in the use of construction project management information and software systems. Manual data collection is expensive, error prone, and inaccurate (Navon \& Sacks, 2007; Navon \& Shpatnitsky, 2005; Grau and Caldas 2009). Russell and Fayek (1994) stated that collected construction data are inaccurate to a large extent.

Automated data-collection, analysis and reporting methods have been devised as a partial solution to the stagnant project controls capability (Rebolj et al., 2008). Back and Bell (1995) showed, through a simulation technique, that internal information integration in industrial capital projects could improve both project cost and time outcomes. Griffis et al. (1995) studied the effects of 3D CAD models on project cost, schedule, and rework and found improvement in the three performance facets. Johnson and Clayton (1998) suggested that team productivity and management procedures may improve by adopting information technologies. Back and Moreau (2000) indicated that information integration within and across organizational boundaries can reduce project time and cost at completion. One of the first efforts to quantify the benefits of information technology adoption was by Thomas et al. (2001). The authors evaluated the impact of design/information technology (D/IT) adoption on project performance metrics such as cost, schedule, and safety. Specifically four technologies were analyzed: (1) integrated database; (2) electronic data interchange (EDI); (3) three-dimensional (3D) information; and (4) computer-aided design (CAD) modeling and bar coding. The authors contended that such technologies can improve project cost and schedule performance. Furthermore, Thomas et al. (2004) conclude that increase of D/IT can result in cost savings of approximately 4\%. Similarly, O'Connor and Yang (2004) conducted a survey on more than 200 capital facility projects and quantified the benefits of information technology adoption on project performance. Performance was analyzed at project level, phase level, for high-tech and low-tech work functions and specifically their relationship with information integration and automation levels. The authors concluded that certain technology advancements can improve project cost, but most likely, schedule performances. With a similar insight, El-Mashaleh et al. (2006) through quantitative analysis found that technology usage has a higher impact on schedule than cost performance. The authors developed an IT rating index similar to that of 0 'Connor and Yang (2004). The analysis showed that one unit of technology improvement can increase schedule performance by $5 \%$ and cost performance by $3 \%$. Kang et al. (2008) concluded that owner companies experience $2 \%$ improvement in cost growth and $17 \%$ improvement in schedule growth through the incorporation of information technologies. Zhai et al. (2009) showed that construction labour productivity is positively related to the use of automation and integration technologies.

\section{Data Collection}

An initial survey was designed and disseminated regarding near real-and real-time control practices. The results revealed that lack of information integration and automated data analytic technologies were key components to real-time project controls. Incidentally, CII Benchmarking and Metrics (BM\&M) database of completed projects characterizes, for each completed project

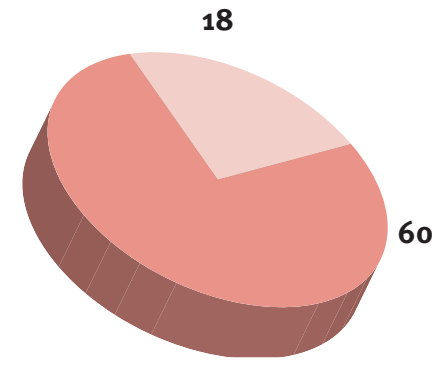

Owner

Contractor

Figure 1: Owner and Contractor submitted projects

and through a 5-point Likert scale, the maturity of internal and external information integration as well as automated data analytics. Thus, these two technologies (information integration and automated data analytics) were used in this study as surrogates of real-time project controls for statistical analysis purposes. Information integration is defined as an information tool that enables the seamless communication of data and information to the organization (internally) or/and to project stakeholders (externally). Automated data analytics is defined as the automation of the analysis of raw data in order to generate information.

In each project within the BM\&M database, automation and integration maturity assessments were defined at each phase of the project, while schedule and cost performance information were defined not only for each phase but also at project completion. A single index of technology maturity consistent with the levels of internal and external integration and automated analytics was defined. For statistical comparison purposes, the sampled projects were grouped into high level of automation/integration and low level of automation/integration. Projects with a high level of automation/integration were defined with a score of 3.5 to 5 , and projects with a low level of automation/integration 
had a maximum score of 2.5. Projects with intermediate scores between 2.5 and 3.5 were not considered so that the disparity between the two other groups could be evident.

A sample of 78 projects with a total installed cost of $\$ 8$ billion was used for statistical analysis purposes. Both owner and contractor completed projects were sampled (Figure 1).

Most projects in the sample were performed in the light and heavy Industrial sector and were located in North America. The majority of the 78 projects had been delivered though Design-Bid-Build, DesignBuild, (or Engineering-ProcurementConstruction), and Parallel Primes. The top project business drivers were Operability and Capacity. The project driver for half of the reported projects was both cost and schedule, while the driver for the other projects was either cost or schedule. In terms of contract types, the presence of cost reimbursable and lump sum contracts was prevalent across project phases. Most projects were defined as either grassroots or modernization (Figure 2).

\section{Findings}

The non-parametric Mann-Whitney test was used in order to determine the significance of the cost and schedule performance difference on projects with high and low level of technology maturity. Although the results were not statistically significant, such results indicate that the seamless communication of information and the ability to generate automated, and hence ondemand, reports can eventually result in large impacts on cost and schedule performance. The results (see Table 1) show that, on average, integration and automation technologies result in improved cost and schedule performances. For instance, higher levels of information integration and automated analytics improve project cost performance at completion by $3.34 \%$. Also, the reader should notice that there is a stronger positive relationship between integration and automation practices and schedule performance than cost performance.

\section{Conclusion}

This study assessed the impact of information aspects related to internal and external integration, and to automated analytics on the final performance of capital projects. Even though the results were not statistically significant, it seems clear from the results that such positive impact can be realized. Additional facets of this study actually characterized that even though such information facets are a critical when optimizing the project controls function, the range of aspects to be attained covered, in addition to controls, organizational behavior and advanced information technology aspects. For instance, work packaging becomes essential in order for project teams to be able to retrieve the required information through estimating, design, and construction, so that information is available to make informed in reliable decisions accross project functions. For instance, we documented that decision makers with accurate and timely information are able to benefit projects, portfolios of capital investment projects, and their organizations alike. Currently, a gap in the reporting cycle exists, so that decisions are made on outdated information. Further research efforts should investigate the impact of information integration and automated analytics by project phase.

\section{Acknowledgements}

We want to acknowledge and thank The Construction Industry Institute for the sponsorship and support to all the aspects reported in this article. We also want to thank all the subject matter experts that contributed to this research effort through the data collection, analysis, and validation steps, and specifically the subject matter experts within CII's Research Team 316.

\section{References}

Abudayyeh, O., Temel, B., Al-Tabtabai, H., \& Hurley, B. (2001). "An intranet-based cost control system." Advances in Engineering Software, 32(2), 87-94.

Arnold, P., Javernick-Will, A. (2012). Projectwide access: Key to effective implementation of construction project management software systems. Journal of Construction Engineering and Management, 139(5), 510-518

Azimi, R., Lee, S., AbouRizk, S. M., \& Alvanchi, A. (2011). A framework for an automated and integrated project monitoring and control system for steel fabrication projects. Automation in Construction, 20(1), 88-97.

Back, W. and Bell, L. (1995). "Monte Carlo Simulation as Tool for Process Reengineering.” J. Manage. Eng., 11(5), 46-53.

Back, W. E., and Moreau, K. A. (2000). “Cost and schedule impacts of information management on EPC process.” J. Manage. Eng., 16(2), 59-70.

Back, W.E., and Grau, D. (2013). "Four-casting for Early and Accurate Predictability." RS291-1, Construction Industry Institute, The Univ. of Texas at Austin, Austin, TX.

Barraza, G. A., Back, W. E., \& Mata, F. (2000). Probabilistic monitoring of project performance using SS-curves. Journal of Construction Engineering and Management, 126(2), 142-148.

Burati, J.L.J., Farrington, J.J., Ledbetter, W.B., (1992). "Causes of quality deviations in design and construction.” J. Constr. Eng. Manage., 118 (1), 34-49.

Cabano, S. L. (2003). Regaining control of project control. AACE International.Transactions of the Annual Meeting, , CSC111-CSC116.

Chang, A.S. (2002). "Reasons for cost and schedule increase for engineering design projects." J. Manage. Eng., 10.1061/ (ASCE)0742-597X(2002)18:1(29), 29-36.

Choo, H., Tommelein, I., Ballard, G., and Zabelle, T. (1999). "WorkPlan: Constraint-Based Database for Work Package Scheduling." J. Constr. Eng. Manage., 125(3), 151-160.

Elbeltagi, E., \& Dawood, M. (2011). Integrated visualized time control system for repetitive construction projects. Automation in Construction, 20(7), 940-953. 


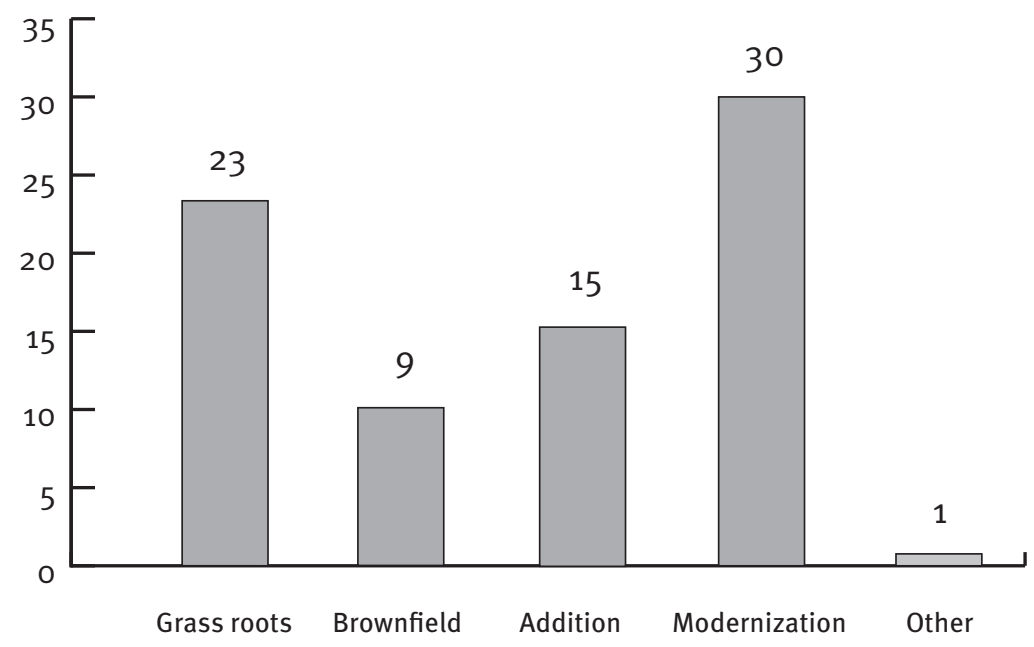

Figure 2: Number of projects by project nature

El-Mashaleh, M., O’Brien, W. J., and Minchin, R. E. (2006). "Firm performance and information technology utilization in the construction industry." J. Constr. Eng. Manage., 1325, 499-507.

Grau, D., and Back, W.E. (2015). “The Predictability Index - Novel Metric to Assess Cost and Schedule Performance." ASCE, Journal of Construction Engineering and Management, 04015043-1 to -8.

Grau, D., Caldas, C. H. (2009). Methodology for automating the identification and localization of construction components on industrial projects. Journal of Computing in Civil Engineering, 23(1), 3-13.

Grau, D., Zeng, L., \& Xiao, Y. (2012). Automatically tracking engineered components through shipping and receiving processes with passive identification technologies. Automation in Construction, 28, 36-44.

Griffis, F. H., Hogan, D. B., and Li, W. (1995). "An analysis of the impacts of using three dimensional computer models in the management of construction." Research Rep.
No. 106-11, Construction Industry Institute (CII), Austin, Tex.

Gunduz, M., and Hanna, A. S. (2005). "Benchmarking change order impacts on productivity for electrical and mechanical projects." Build. Environ., 40(8), 1068-1075.

Howell G, and Ballard G. (1997). Lean Construction Factors Affecting Project Success in the Piping Function. L. Alarcon, ed., AA Balkema, Rotterdam, The Netherlands.

lbbs, W. (2013). “Thinking about Delay, Disruption, and the Cumulative Impact of Multiple Changes.” J. Leg. Aff. Dispute Resolut. Eng. Constr., 10.1061/(ASCE) LA.1943-4170.0000126, 109-112.

Johnson, R. E., and Clayton, M. J. (1998). “The impact of information technology in design and construction: The owner's perspective." Autom. Constr., 8(1), 3-14.

Kang, Y., O’Brien, W., Thomas, S., and Chapman, R. (2008). "Impact of Information Technologies on Performance: Cross Study Comparison." J. Constr. Eng. Manage., 134(11), 852-863.
Kim, B. C., \& Reinschmidt, K. F. (2009). Probabilistic forecasting of project duration using Bayesian inference and the beta distribution. Journal of Construction Engineering and Management, 135(3), 178186.

Mulva, S. P. and Dai, J. (2012). "Performance assessment." Construction Industry Institute, The Univ. of Texas at Austin, Austin, TX.

Navon, R., Sacks, R., (2007). Assessing research issues in Automated Project Performance Control (APPC), Automation in Construction, Volume 16 (4), 474-484

Navon, R., Shpatnitsky, Y., (2005). Field experiments in automated monitoring of road construction, J. Constr. Eng. Manage., 131 (4), 487-493.

Nieto-Morote, A., \& Ruz-Vila, F. (2011). A fuzzy approach to construction project risk assessment. International Journal of Project Management, 29(2), 220-231.

O’Connor, J. T., and Yang, L. R. (2004). “Project performance versus use of technologies at project and phase levels." J. Constr. Eng. Manage., 130(3), 322-329.

\begin{tabular}{|c|c|c|c|c|}
\hline \multirow[b]{2}{*}{ Project Type } & \multicolumn{2}{|r|}{ Cost } & \multicolumn{2}{|c|}{ Schedule } \\
\hline & $\begin{array}{c}\text { Count } \\
\text { (low, high) }\end{array}$ & Average Performance Impact & $\begin{array}{c}\text { Count } \\
\text { (low, high) }\end{array}$ & $\begin{array}{c}\text { Average Performance } \\
\text { Impact }\end{array}$ \\
\hline All & 21,14 & $3.34 \%$ & 19,15 & $5.31 \%$ \\
\hline Grassroots and Brownfield & 7,7 & $6.53 \%$ & 8,8 & $15.80 \%$ \\
\hline
\end{tabular}


Rebolj, D., Babič, N. Č., Magdič, A., Podbreznik, P., \& Pšunder, M. (2008). Automated construction activity monitoring system. Advanced engineering informatics, 22(4), 493-503.

Rojas, E. and Songer, A. (1999). "Web-Centric Systems: A New Paradigm for Collaborative Engineering.” J. Manage. Eng., 15(1), 39-45.

Rozenes, S., Vitner, G., \& Spraggett, S. (2006). Project control: literature review. Project Management Journal

Russell, A. and Fayek, A. (1994) Automated corrective action selection assistant. Journal of Construction Engineering and Management, 120(1), 11-33.

Thomas S. R., Tucker R.L., and Kelly R.W. (1997). An assessment tool for improving team communications. Technical Report, RR10511., Construction Industry Institute (CII), Texas, Austin.

Thomas, S., Lee, S., Spencer, J., Tucker, R., and Chapman, R. (2004). "Impacts of Design/Information Technology on Project Outcomes.” J. Constr. Eng. Manage., 130(4), 586-597
Thomas, S., Macken, C., and Lee, S. (2001). "Impacts of design/information technology on building and industrial projects." NIST GCR 01-828, National Institute of Standards and Technology, Washington, D.C.

Thompson PA, Perry JG. Engineering construction risks: a guide to project risk analysis and risk management. London: Thomas telford, 1992.

Toor, S.-U.-R., and Ogunlana, S. O. (2008).

"Problems causing delays in major construction projects in Thailand." Constr. Manage. Econ., 26(4), 395-408.

Ye, G., Jin, Z., Xia, B., and Skitmore, M. (2014). "Analyzing Causes for Reworks in Construction Projects in China.” J. Manage. Eng., 10.1061/(ASCE)ME.1943-5479.0000347, 04014097.

Zhai, D., Goodrum, P., Haas, C., and Caldas, C. (2009). "Relationship between Automation and Integration of Construction Information Systems and Labor Productivity." J. Constr. Eng. Manage., 135(8), 746-753. 